\title{
Thermal Effect Analysis of Laser Processing Cemented Carbide Micro-texture
}

\author{
Quan Wan*, Minli Zheng, Shucai Yang \\ Harbin University of Science and Technology, Harbin 150080, China
}

Corresponding Author Email: wq@ @rbust.edu.cn

https://doi.org/10.18280/ijht.370108

Received: 21 July 2018

Accepted: 29 October 2018

\section{Keywords:}

micro-texture, heat affected zone, element change, micro-cracks

\begin{abstract}
Laser surface microtexturing techniques can improve the friction properties of materials by reducing the contact area and form heat affected zones (HAZ) by energy conduction in laser processing. HAZ has a significant effect on the surface friction properties in the friction zone. This paper focuses on the formation of HAZ on the surface of cemented carbide during laser processing micro-texture. Firstly, the principle of energy absorption, conversion and conduction in laser processing is analyzed. Then the finite element method is used to study the distribution of temperature field and its change with time. Then the laser processing of microtexture of cemented carbide is carried out by laser marking machine. In the experiment, the characteristics of HAZ on the surface of cemented carbide after laser processing were studied by ultra-depth microscope, EDS and SEM. The effects of different laser processing parameters on the size of HAZ were studied, and the changes of element content after laser processing were studied. At the same time, the morphology of HAZ microcracks was observed and the reasons for its formation were analyzed. The results show that the laser power is the main factor affecting the HAZ size, followed by the laser scanning speed and the number of scans. The content of Co after laser processing is highest near the center of the micro-texture, and decreases from the center to the edge. The thermal stress and stress concentration caused by the temperature gradient cause microcracks to form around and inside the microtexture. By selecting reasonable laser parameters, it has an important influence on the size, element content and microcrack formation of HAZ, and it is of great significance to improve the micro-texture properties of the processed cemented carbide.
\end{abstract}

\section{INTRODUCTION}

Cemented carbide is a kind of alloy material, which is made up of refractory metal compound $\mathrm{WC}$ and $\mathrm{Co}$ binder. Cemented carbide has many excellent properties, such as high hardness, wear resistance, good strength, toughness, and heat resistance, etc. It also has good chemical stability in a high temperature environment. Due to its excellent performance, it is used widely in tool materials especially for the tools processing hard materials. In order to further improve the surface properties of cemented carbide material, laser surface treating technique has become an important mean.

In recent years, there are many scholars who study microtexture cutting tools, among which laser processing is the most common method. Laser processing itself belongs to thermal processing. Laser ablation in cemented carbide materials will inevitably change its material properties, such as chemical elements, metallographic structure, residual stress and so on, which have an impact on the cutting performance of cutting tools. Therefore, at present, some scholars have studied the laser strengthening of cemented carbide surface and the mechanism of laser on cemented carbide, mainly from the following two aspects.

Changing the microstructure and mechanical properties of the laser heat treatment of YG8 cemented carbide and that results show that the tool service life after laser heat treatment is $20 \%$ higher than the tool without heat treatment, and the production efficiency and processing quality will be improved accordingly [1]. Laser cladding cemented carbide has high wear resistance by investigating the microstructure and wear properties of WC/Ni alloy after laser cladding [2]. High energy irradiation treating changes the surface hardness and wear resistance of alloying materials, experimental results show that $\mathrm{TiC}$ and $\mathrm{TiB}$ precipitate on the marten site. This kind of microstructure improves the hardness and wear resistance of the alloy surface [3].

Karatas [4] and others have studied the laser treatment of cemented carbide tools. In this study, they used a laser to heat the surface of cemented carbide cutters. By studying the temperature field in the irradiation area, the temperature gradient is obtained and the cooling rate in the surface area is predicted. At the same time, the microstructures of laserheated surfaces were analyzed. The fracture toughness of laser-heated surfaces was measured by indentation test. It was found that $\mathrm{Co}$ and $\mathrm{TiC}$ melted during heating, because their thermal conductivity was lower than $\mathrm{WC}$, higher cooling rate and surface temperature gradient resulted in higher thermal stress on laser-treated surfaces. The multi-directional cracks and tungsten nitride formed on the tool surface were observed and measured by XRD. Finally, it is concluded that the thermal integration of binder and carbide compounds on the surface of laser-processed tool surface is formed, which in turn improves the micro-structure of laser beam irradiation in this area.

Shan [5] firstly studied the experiment and application of laser surface strengthening of cemented carbide. Through the experiment of laser hardening treatment of cemented carbide cutting tools, he strongly proved that laser surface hardening treatment has a remarkable effect on improving the bending 
strength and wear resistance of cemented carbide products. $\mathrm{Lu}$ Dongsheng [6] studied the surface strengthening of cemented carbide by laser heat treatment. The conclusion was drawn that the mechanical properties of cemented carbide could be improved obviously by choosing reasonable laser quenching process parameters and blackening condition. The mechanism of the change of structure and properties of laser treated cemented carbide was discussed and analyzed. Urbina [7] carried out the experiment of ultrashort pulse laser ablation of cemented carbide, and carried out analysis and research. In this study, a systematic method is proposed. Firstly, the most significant variables affecting the target are searched and used to plan and design experiments. Secondly, considering the interaction between Beer-Lambert law and incubation effect, the laser ablation phenomena of existing materials are analyzed.

Except for experimental methods, many researchers adopt finite element methods to investigate the effect of laser processing on cemented carbide. The profile and depth on the surface of material under different laser parameters by finite element method, which provides basis of modified laser machining parameters such as laser energy density and wavelength for different material [8-11]. The surface remelting treatment of electrics melting $\mathrm{WC}$ steel composite material DGW40 and DGW50 by $\mathrm{CO}_{2}$ laser was studied. Results show that the substrate surface microstructure is refining after laser treatment, and the micro hardness and wear resistance of the surface are better than the substrate itself [12]. The laser drilling thermodynamic model was established through the finite element method, and studied the influence of laser energy, pulse width and repetition frequency on the $\mathrm{HAZ}$, and corresponding laser parameters were determined to get high processing efficiency and small HAZ [13]. Temperature field gradient near the laser weld zone is larger and the temperature exponentially increases and decays [14, $15]$.

Through test of the micro-structure property of HAZ on substrate. Results show that the multiple remelting can effectively eliminate the quenching microstructure of HAZ, and multiple thermal cycling by remelting has large influence on the properties of HAZ especially the hardness [16]. The surface microstructure after laser processing become dense; the hardness increases, and the surface friction coefficient decreases compared to the untreated [17, 18]. Enthalpy method was used to calculate the relationship between temperature and micro cracks and pores were found on the laser ablation region [19]. Laser surface alloying of martensitic stainless steel for properties improvement by using the $\mathrm{CO} 2$ laser and it has the significant progress in improving the properties of martensitic stainless steel has been reported [20, 21]. The hardness of material such as various stainless steels had been improved through laser alloying by incorporating carbide and borides [22-25]. Existing studies have focused on predicting the LSP introduced residual stress [26-29], but very limited work has given attention to further heat effect zone under laser processing.

Laser processing of micro-texture is widely used in many fields of manufacturing because of its high energy density, good processing controllability, fast processing speed and easy to achieve precision processing. Laser processing technology is also the most widely used method of cutting tool surface texture. From a technical point of view, although the laser beam is only irradiated and used as the surface layer of cemented carbide materials, due to the high energy density of the laser beam, there is also a decreasing radiation extension area under the surface. Therefore, when the volume of cemented carbide is small and many sides are irradiated, the bending strength of cemented carbide materials will be improved significantly. From the test data of cemented carbide samples and its practical application effect, laser surface strengthening technology is effective in optimizing the modification of cemented carbide materials, and has significant economic benefits. Most of the above research work is based on the application of laser processing cemented carbide technology, and there is no deeper theoretical and mechanism discussion.

In this paper, the interaction mechanism between laser and cemented carbide materials is deeply studied, and the formation mechanism of HAZ on the surface of cemented carbide during laser processing of micro-texture is studied. By analyzing the principle of energy absorption, conversion and transmission in laser processing, the temperature field distribution and its change with time in laser processing are designed by finite element method, and the distribution law of heat affected zone is obtained.

In summary, the finite element method is used to study the temperature field distribution of laser treated cemented carbide, and it is of great significance to study the influence of temperature distribution on the surface properties of cemented carbide materials. It is necessary to predict and control the reasonable laser parameters through the relationship between the laser parameters and the temperature field.

\section{FINITE ELEMENT SIMULATION}

\subsection{LSP and heat flex mode}

In processing of laser shock, laser energy irradiates on surface of material, the main interaction includes energy absorption, conversion and conduction, and it is showed in Figure 1. The simulation model was built by ANSYS and showed in Figure 2. The physical parameters of cemented carbide are listed in Table 1

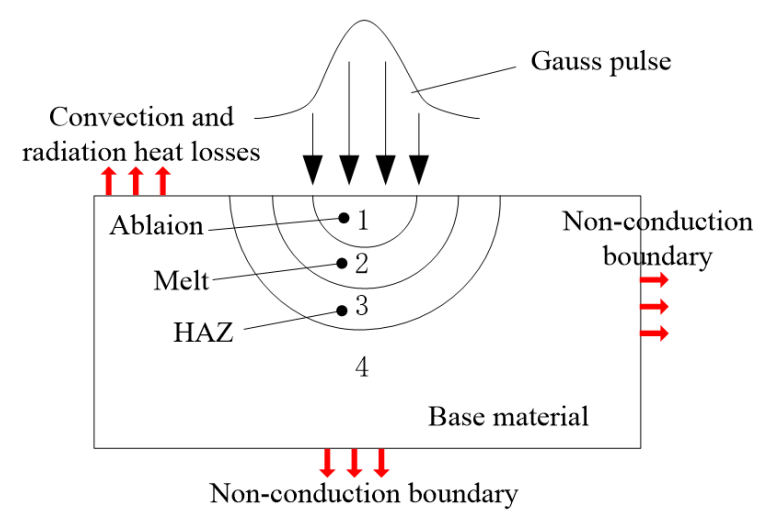

Figure 1. LSP model

In Figure 1, the numeral "1" indicates an ablated region, the numeral "2" indicates a molten recast region, the numeral " 3 " indicates a heat affected zone, and the numeral "4" indicates an unaffected zone. The heat source of the laser beam mainly includes a point heat source and a surface heat source. The surface heat source is usually defined as a Gaussian heat source. The laser beam spot radius is assumed to be $r$, the laser 
beam irradiation area is $\pi r^{2}$, and the laser beam power is $P$. The power density equation of the laser beam is as follows:

$$
P(x, y)=\frac{P}{\pi r^{2}}
$$

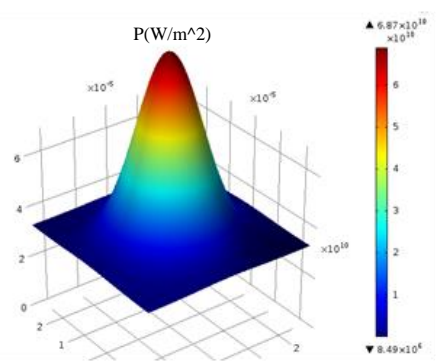

(a) Energy density
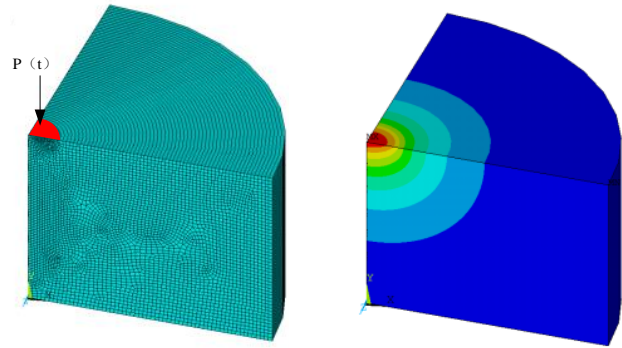

(b) Mesh distribution (c) Temperature distribution

Figure 2. Simulation model

Table 1. Physical parameters of cemented carbide (YG8)

\begin{tabular}{c|c|c|c|c}
\hline $\begin{array}{c}\text { Specific } \\
\text { Heat } \\
\text { J/(kg.K) }\end{array}$ & $\begin{array}{c}\text { Thermal } \\
\text { Conductivity } \\
\mathbf{W}(\mathbf{m} . K)\end{array}$ & $\begin{array}{c}\text { Density } \\
\mathbf{k g} / \mathbf{m}^{\mathbf{3}}\end{array}$ & $\begin{array}{c}\text { Melting } \\
\text { Temp } \\
\mathbf{K}\end{array}$ & $\begin{array}{c}\text { Gasification } \\
\text { Temp } \\
\mathbf{K}\end{array}$ \\
\hline 175.9 & 75.4 & 14700 & 3050 & 6000 \\
\hline
\end{tabular}

\subsection{Simulation results and discussion}

When the laser power is $30 \mathrm{~W}$, the temperature field graph was showed in Figure 2(c), according to physical parameter of cemented carbide in Table 1 , the melting temperature is $3050 \mathrm{~K}$, the gasification temperature is $6000 \mathrm{~K}$. After the laser treatment of the surface of the cemented carbide, ablation occurs at a temperature higher than $6000 \mathrm{~K}$, and melting occurs at a temperature between $3050 \mathrm{~K}$ and $6000 \mathrm{~K}$. Since the temperature of the phase change is about $1000 \mathrm{~K}$, the heat affected zone (HAZ) temperature is defined as between 1000 $\mathrm{K}$ and $3050 \mathrm{~K}$.

Following the Figure 3, the temperature distribution along axis of $\mathrm{x}$ and $\mathrm{y}$ are showed. After laser irradiation, the temperature near the center of the point is higher than the boundary in the $\mathrm{x}$ direction due to vaporization, and the distance from the center decreases. The temperature of WC is about $6000 \mathrm{~K}$. When the temperature is higher than $6000 \mathrm{~K}$, some materials are ablated, and the phase transition of cemented carbide is about $1000 \mathrm{~K}$. When the temperature is higher than 1000K, HAZ is defined. During the simulation, the cycle time: $n=1$, laser scanning speed: $v=100$, laser spot radius: $r=0.025 \mathrm{~mm}$, laser wavelength: $\lambda=1064 \mathrm{~nm}$; The simulation results are shown in Figure 3. Temperature distribution along $\mathrm{X}$ is shown in Figure 3(a), from Figure 3(a), the ablation area increases with the increase of laser power. Form Figure 3(b), the ablation area along $\mathrm{X}$ bigger than along $\mathrm{Y}$.

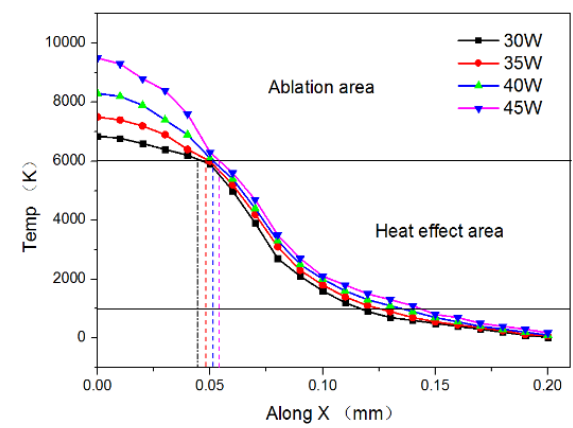

(a)

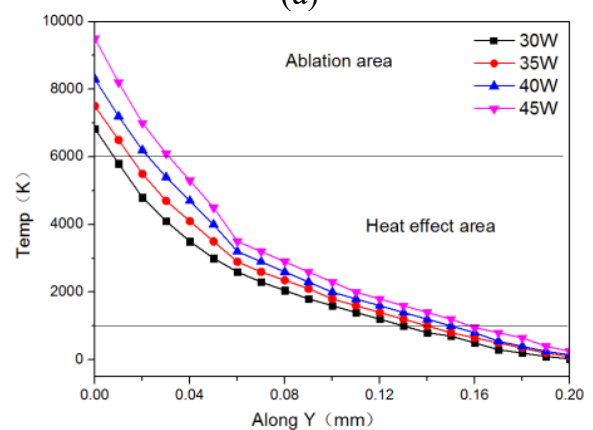

(b)

Figure 3. Temperature distribution along different direction of $\mathrm{X}$ and $\mathrm{Y}$

In this section, the effects of laser power, scanning speed and number of scans on the size of the heat affected zone are studied according to the distribution of the temperature field. The results are shown in Figure 4. The results show that with the increase of laser scanning speed, the size of the heataffected zone decreases. With the increase of the number of scans, the size of the heat-affected zone increases gradually. With the increase of laser power, the heat-affected zone increases significantly.

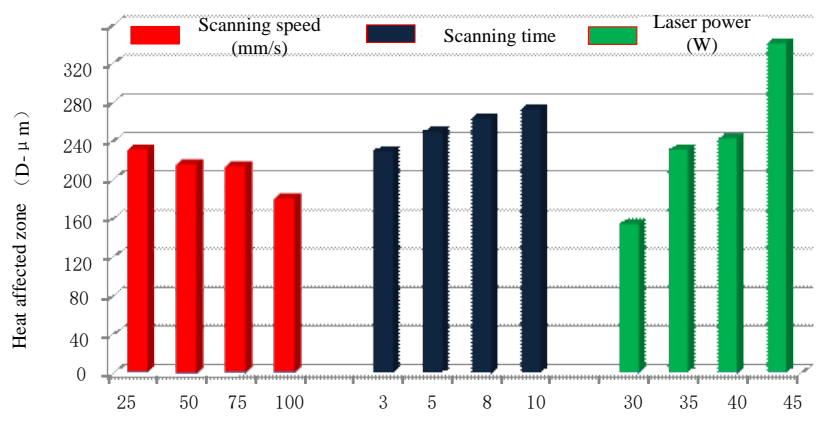

Figure 4. HAZ of different laser parameters on the surface temperature of materials

\section{EXPERIMENT}

\subsection{Material and specimens}

The fiber laser mark machine is used to machine microtextures with different sizes on the surface of cemented carbide by different laser processing parameters, including spot diameter, output power, scanning speed and processing times. The tool material used in the experiment is cemented carbide YG8. The micro-textures are made by laser near the main cutting edge on the rake face of cutting tool. The shape of 
micro-texture is circular with a certain depth. The size of HAZ was measured by the ultra-deep field microscope, and the surface morphology characteristics of the micro-textures were observed by SEM. The experimental equipment is shown in Figure 5.

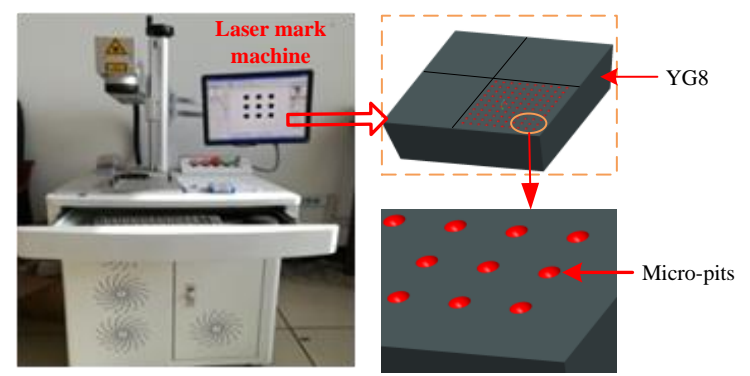

Figure 5. Schematic representation of micro-pits machining

Micro-pits texture can't be formed when the laser energy is very small, but a lot of micro crack appeared in the interior of laser spot, as shown in Figure 6, the cycle time: $n=1$, laser scanning speed: $v=100 \mathrm{~mm} / \mathrm{s}$, laser spot radius: $r=0.025 \mathrm{~mm}$, laser wavelength: $\lambda=1064 \mathrm{~nm}$, laser power: $P=20 \mathrm{~W}$; From Figure 7(a), the area of laser spot processing is marked, the different location morphology are marked in interior of laser spot. Mark 1 and Mark 3 are located at the center of the spot, so the laser has the largest energy, the gap between the cracks is the largest; Mark 2 and Mark 4 are at the edge of the spot, the crack gap is small.
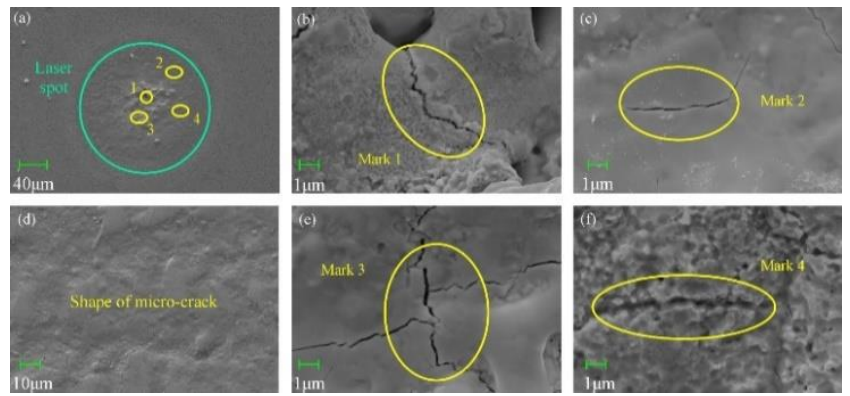

Figure 6. Micro crack SEM

\subsection{Micro-pit measurements}

The micro pits can be formed when laser energy is high enough. In this experiment, the laser spot diameter is $50 \mu \mathrm{m}$; the laser scanning speed is $100 \mathrm{~mm} / \mathrm{s}$; laser power is $30 \mathrm{~W}, 35$ $\mathrm{W}, 40 \mathrm{~W}, 45 \mathrm{~W}$ respectively. The micro-pit-textures machined by laser on the surface of cemented carbide are shown in Figure 7. Apparent HAZ can be seen around the micro-texture. The HAZ sizes of micro-pit-texture under different laser parameters are measured. When the laser power is small, the diameter of the micro hole is approximately equal to the laser spot diameter. When the laser power is greater than $40 \mathrm{~W}$, the diameter of the micro hole is larger than the diameter of the laser spot. Hence, in order to ensure the machining accuracy of micro pits, it is not suitable to use larger power laser parameters, and the laser power should be kept between $30 \mathrm{~W}$ $40 \mathrm{~W}$.
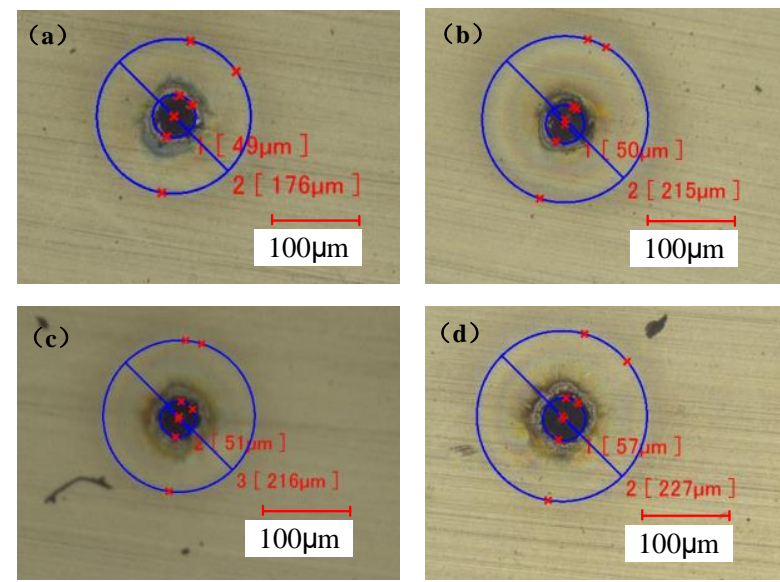

Figure 7. Micro-pits measurement a) $P=30 \mathrm{~W}$; b) $P=35 \mathrm{~W}$; c) $P=40 \mathrm{~W}$; d) $P=45 \mathrm{~W}$

\section{ELEMENTS DISTRIBUTION AROUND OF MICRO- PIT}

High temperatures are generated during laser processing of micro-textures in cemented carbides. However, high temperatures can cause various chemical reactions on the surface of cemented carbide tools, especially in the air. Since the heat affected zone is different due to the difference between the laser power and the number of scans, the temperature of the heat affected zone also changes, so that the heat affected zone undergoes different degrees of oxidation after the laser action. The main component of YG8 cemented carbide tool is composed of tungsten carbide and cobalt. Generally, tungsten carbide is stable under high temperature conditions and is not easy to react in air. When cobalt is heated in air to above $300^{\circ} \mathrm{C}$, oxidation occurs. The reaction produces $\mathrm{CoO}$ and $\mathrm{Co}_{3} \mathrm{O}_{4}$, but when the temperature is higher than $900{ }^{\circ} \mathrm{C}$, the final product produced is only $\mathrm{CoO}$.

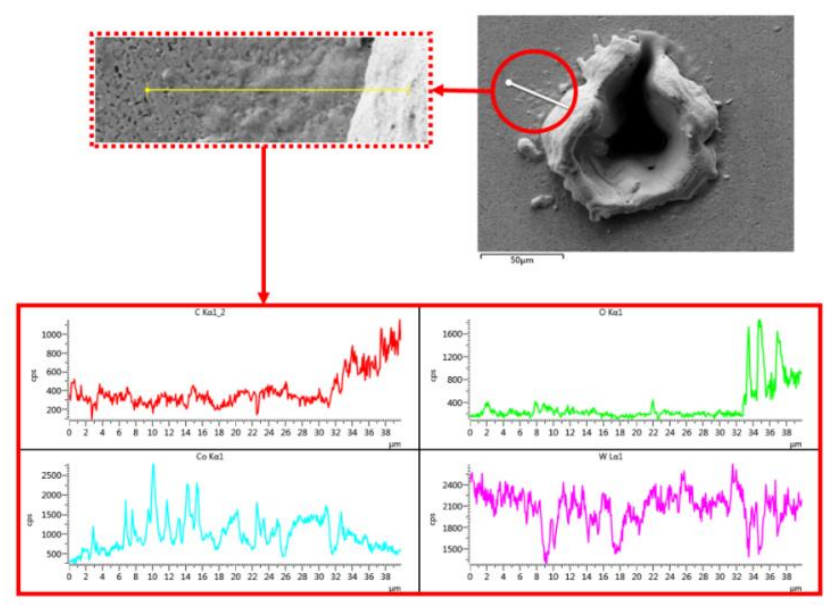

Figure 8. Elements distribution around of micro-pit

The change of element content in the HAZ was analyzed by scanning electron microscope (SEM), and the measurement position is shown in Figure 8. It can be seen from Fig. 8 that the oxidation content of Co is highest near the center of microtexture where the temperature is highest, and the oxidation degree of Co is also decline from the center to the edge as the decrease of temperature. The content of oxygen element also 
has the same tendency with Co element. Cobalt oxide is a compound that is unstable and cannot be in a free state. Therefore, cobalt oxide near the micro-texture may reduce the cutting performance of the tool.

\section{CONCLUSIONS}

In laser processing parameters, the main factors affecting the size of heat affected zone are laser power, laser scanning speed and scanning times. According to the importance, the order of influencing factors is: laser power $>$ laser scanning speed $>$ scanning times.

When the laser power is too small, only the surface of the material will be ablated, and micro-cracks will be formed on the surface of the material, so the micro-texture can not be processed. When the laser power is too high, it can not guarantee the processing accuracy of micro-pits, nor can it produce reasonable micro-texture. The most reasonable laser power chosen in this paper is $30-40 \mathrm{~W}$.

Oxidation reaction occurs in the HAZ after laser processing. The content of Co is highest near the center of micro-texture and decline from the center to the edge. The content of oxygen element also has the same tendency with Co element.

\section{ACKNOWLEDGEMENT}

This project is supported by National Natural Science Foundation of China (No. 51875144).

\section{REFERENCES}

[1] Lv DS, Li JS, Wang SZ. (1998). Effects of laser heating treatment on microstructures and mechanical properties of hard alloy YG8. Transactions of Metal Heat Treatment 19(3): 60-62. https://doi.org/10.13289/j.issn.10096264.1998.03.013

[2] Yang JX, Zuo TC, Wang XB, Liu HD. (2008). The microstructure and wear-resistant properties of $\mathrm{WC} / \mathrm{Ni}$ based cemented carbide fabricated by laser cladding. Applied Laser 28(6): 450-454.

[3] Lee CS, Oh JC, Lee S. (2003). Improvement of hardness and wear resistance of $(\mathrm{TiC}, \mathrm{TiB}) / \mathrm{Ti}-6 \mathrm{Al}-4 \mathrm{~V}$ surfacealloyed materials fabricated by high-energy electronbeam irradiation. Metallurgical and Materials Transactions A (Physical Metallurgy and, Materials Science) 34(7): 1461-1471. https://doi.org/10.1007/s11661-003-0258-y

[4] Karatas C, Yilbas BS, Aleem A, Ahsan M. (2007). Laser treatment of cemented carbide cutting tool. Journal of Materials Processing Technology 183(2-3): 234-240. https://doi.org/10.1016/j.jmatprotec.2006.10.012

[5] Shan SJ. (1997). Experiment and application of laser to strengthing hard metals surface. Rare Metals and Cemented Carbides (128): 25-27.

[6] Lv DS, Tang BJ, Li JS. (1998). Study on surface enhancement of harden alloy of laser heat treatment. Journal of Jilin University of Technology 28(2): 110-112. https://doi.org/10.13229/j.cnki.jdxbgxb1998.02.022

[7] Urbina JP, Calderón DC, Emmelmann C. (2013). Experimental and analytical investigation of cemented tungsten carbide ultra-short pulse laser ablation. Physics
Procedia 41(Complete):

$752-758$.

https://doi.org/10.1016/j.phpro.2013.03.144

[8] Souad T, Mounir Z, Abdelwahab B, Salah H. (2018). Numerical simulation EF/VOF to study the influence of the surface condition of the formation of the slats of a nickel deposit produced by plasma spraying. Annales de Chimie - Science des Matériaux 42(2): 165-180. https://doi.org/10.3166/ACSM.42.165-180

[9] Zhang JQ, Li JM, Lu CH, Fang XX, Ma Z. (2014). Research progress of numerical simulation of laser thermal effects. Journal of Mechanical \& Electrical Engineering 31(11): 1317-1324. https://doi.org/10.3969/j.issn.1001-4551.2014.11.001

[10] Amiri R, Bouiadjra BB, Amiri A, Haref DC. (2018). 3D finite element analysis of stem-cement interface under cavity effect. Revue des Composites et des Matériaux Avancés 28(4): 455-469. https://doi.org/10.3166/RCMA.28.455-469

[11] Lim HS, Yoo J. (2011). FEM based simulation of the pulsed laser ablation process in nanosecond fields. Journal of Mechanical Science and Technology 25(7): 1811-1816. https://doi.org/10.1007/s12206-011-0511-z

[12] You X, Zhang C, Liu N. (2008). Laser surface melting of electro-metallurgic WC/steel composites. Journal of Materials Science 43(8): 2929-2934. https://doi.org/10.1007/s10853-007-1798-0

[13] Wu XJ, Zou DW, Xu F. (2010). FEM Analysis on the temperature field of CVD diamond film laser drilling. Bulletin of the Chinese Ceramic Society 29(01): 83-88. https://doi.org/10.16552/j.cnki.issn10011625.2010.01.041

[14] Lu Y, Zhang J, Hu JP. (2012). Modeling and simulation of laser welding for aluminum alloy. Hot Working Technology 41(1): 130-133. https://doi.org/10.1007/s11783-011-0280-z

[15] Song LS, Shi GQ, Li ZG. (2006). Simulation on laser drilling temperature field by using ANSYS. Acta Armamentarii 27(5): 879-882. https://doi.org/10.3969/j.issn.1672-9870.2006.04.006

[16] Wen RJ, Tan H, Zhang FY. (2012). The optimization of microstructures and properties in heat affect zone of the base in laser solid formed TC4. Applied laser 32(2): 9195.

[17] Popoola P, Fatoba OS, Popoola OM. (2016). The influence of heat treatment and process parameters optimization on hardness and corrosion properties of laser alloyed X12CrNiMo steel. Silicon 8(4): 579-589. https://doi.org/10.1007/s12633-016-9434-8

[18] Peng C, Meng Y, Guo W. (2016). Influence of laser shock processing on WC-Co hardmetal. Advanced Manufacturing Processes 31(6): 794-801. https://doi.org/10.1080/10426914.2015.1058946

[19] Tangwarodomnukun V. (2017). Overflow-assisted laser machining of titanium alloy: Surface characteristics and temperature field modeling. International Journal of Advanced Manufacturing Technology 88(1-4): 147-158. https://doi.org/10.1007/s00170-016-8728-8

[20] Wu Y, Ming T, Li X. (2014). Numerical simulations on the temperature gradient and thermal stress of a thermoelectric power generator. Energy Conversion and Management 88: 915-927. https://doi.org/10.1016/j.enconman.2014.08.069

[21] Adebiyi DI, Fedotova T, Pityana SL, Popoola API. (2011). Improved hardness of laser alloyed X12CrNiMo 
martensitic stainless steel. International Journal of Physical Sciences 6: 3336-3346.

[22] Kim TH, Kim BC. (1992). Chromium carbide laser-beam surface-alloying treatment on stainless steel. Journal of Materials $\quad$ Science 27(11): 2967-2973. https://doi.org/10.1007/bf01154107

[23] Quazi MM, Fazai MA, Haseeb ASMA. (2015). Laserbased surface modifications of aluminum and its alloys. Critical Reviews in Solid State and Materials Sciences 41(2): $1-26$. https://doi.org/10.1080/10408436.2015.1076716

[24] Lo KH, Cheng FT, Kwok CT. (2003). Improvement of cavitation erosion resistance of AISI 316 stainless steel by laser surface alloying using fine WC powder. Surface and Coatings Technology 165(3): 258-267. https://doi.org/10.1016/s0257-8972(02)00739-9

[25] Popoola API, Ochonogor OF, Abdulwahab M. (2012). Microhardness and wear behaviour of surface modified Ti6Al4V/Zr-TiC metal matrix composite for advanced material. Journal of Optoelectronics and Advanced Materials 14: 991-997.
[26] Zhou Z, Bhamare S, Ramakrishnan G, Mannava S, Langer K, Wen Y, Qian D, Vasudevan V. (2012). Thermal relaxation of residual stress in laser shock peened Ti-6Al-4V alloy. Surface and Coatings Technology 206(22): 4619-4627. https://doi.org/10.1016/j.surfcoat.2012.05.022

[27] Buchanan DJ, John R. (2008). Relaxation of shot-peened residual stresses under creep loading. Scripta Materialia 59(3): 286-289. https://doi.org/10.1016/j.scriptamat.2008.03.021

[28] Aghdam AB, Chakherlou TN, Saeedi K. (2010). An FE analysis for assessing the effect of short-term exposure to elevated temperature on residual stresses around cold expanded fastener holes in aluminum alloy 7075-T6. Materials \& Design 31(1): 500-507. https://doi.org/10.1016/j.matdes.2009.06.024

[29] Zhou Z, Gill AS, Qian D. (2011). A finite element study of thermal relaxation of residual stress in laser shock peened IN718 superalloy. International Journal of Impact $\begin{array}{lll}\text { Engineering } & 38(7) \text { : 590-596. }\end{array}$ https://doi.org/10.1016/j.ijimpeng.2011.02.006 